\title{
Predictors of Academic and Social Success and Psychological Well-Being in College Students
}

\author{
Jill M. Norvilitis and Howard M. Reid \\ Department of Psychology, Buffalo State College, 1300 Elmwood Ave., Buffalo, NY 14222, USA \\ Correspondence should be addressed to Jill M. Norvilitis, norviljm@buffalostate.edu
}

Received 29 March 2012; Revised 17 September 2012; Accepted 23 September 2012

Academic Editor: Yi-Shun Wang

Copyright ( $) 2012$ J. M. Norvilitis and H. M. Reid. This is an open access article distributed under the Creative Commons Attribution License, which permits unrestricted use, distribution, and reproduction in any medium, provided the original work is properly cited.

\begin{abstract}
The present study utilized 217 student participants to examine academic, circumstantial, and personal predictors of four categories of college success. Although study skills were most important in predicting grade point average, other factors, including parental encouragement of intellectual curiosity during childhood, ADHD symptomatology, appreciation of the liberal arts, and varying motives to attend college, were also predictive of success, as indicated by measures of academic adjustment, social adjustment, and satisfaction with life. The results replicate previous research indicating that study skills, ADHD symptomatology, and motives to attend college are predictors of various measures of college success and extend prior work by establishing a relationship between college success and two additional variables, parental encouragement of intellectual curiosity and the correspondence between student and institutional values.
\end{abstract}

\section{Introduction}

Predictors of academic and social success and psychological well-being in college students determining the factors that influence student success in college is an important research question. For students, successful completion of college provides affirmation that they have achieved a noteworthy educational goal that has significant implications for their futures. Student success is also important for the institutions of higher education they attend, for it provides confirmation of the relevance of their mission and the effectiveness of their educational programs and support services. And, of course, student success is important for the students' families, as well as for the future of our society, which is heavily dependent upon a well-educated citizenry.

Not surprisingly, due to the recognition of the importance of student success, there have been numerous studies that have examined variables which lead to either its enhancement or diminishment. Early studies noted, for instance, that college success, as measured by college grade point average (GPA), was positively correlated with high school success as measured by high school GPA as well as achievement tests [1], and these variables continue to be identified as predictors of subsequent academic success [2, 3]. Additional variables, such as mastery of study skills, have also been found to be positively associated with college GPA [4] while symptoms such as hyperactivity and inattention, which have been linked with ADHD, have been found to be negatively associated with college GPA [5].

However, college success involves more than just the student's GPA. More recently, therefore, attention has broadened to include other factors that define college success. For instance, a major factor is how well a student adapts to college life and its demands. To measure this construct, Baker and Siryk $[6,7]$ developed the Student Adaptation to College Questionnaire. Among the factors that have been found to be related to adaptation to college are student religiosity [8], marriage status [9], and attitudes toward seeking professional counseling [10].

Although student adaptation to college has been studied in some detail, surprisingly few studies have proposed an overall assessment of student satisfaction as a measure of college success $[11,12]$. Though limited, the data available support the view that a general measure of student satisfaction is associated with college GPA and assessments of student adaptation to college $[11,12]$. 
Recently, Kim et al. [13] attempted to organize the numerous predictors of college success that have been reported in the literature into three broad categories. Their academic achievement and aptitude category includes variables such as high school GPA and measures on aptitude tests such as the SAT. The circumstance category includes situational factors, such as socioeconomic status, ethnicity, and geographic location, variables that the student cannot influence easily, if at all. And, finally, the personal category includes factors such as beliefs and preferences. These were judged to be, at least potentially, more amenable to personal control.

The present study utilized the Kim et al. [13] conceptual framework to examine the influence of five potential predictor variables upon four measures of student success in college. The measures of college success included an academic variable (self-reported GPA) as well as measures of social and academic adjustment and, finally, an overall measure of the student's life satisfaction. The predictor variables were chosen to represent two of the three predictive categories proposed by Kim et al. [13], specifically the circumstance and personal categories. We chose to not include the academic achievement and aptitude category as it has been extensively examined previously. The circumstance variables we included were a measure of ADHD symptoms and subject report of the level of parental encouragement for intellectual curiosity received as a child. The personal variables included were measures of mastery of study skills and motives to attend college, as well as a measure of how well the student's and their college's educational values matched.

The five predictors were chosen to provide a mix of variables that had previously been reported to have an association with student success as well as variables that have not been examined previously as predictors of college success. Thus, higher levels of ADHD symptoms have been reported to be negatively associated with college success as measured by academic adjustment and GPA in USA [14] as well as in China [15], and mastery of study skills have been positively associated with GPA and college retention $[4,16]$. Motives to attend college have also been examined. Schab [17] found that female students' motives to attend college included occupational training and intellectual improvement. Intrinsic and extrinsic motivations were identified by Whitehead [18]. More recently, Phinney et al. [19] utilized an ethnically diverse sample of university students and found three additional motives not previously reported for attending college: to help one's family, to prove one's selfworth, and because of encouragement. These three motives and the other motives examined by Phinney and colleagues [19] are included in the present study.

In addition to the three established variables, the present study included two new predictors, one circumstance and one personal. A circumstantial variable, parental encouragement of intellectual curiosity was examined through a recently developed scale [20] to ascertain whether this variable is associated with success in college. Finally, another recently developed scale that measures student appreciation of the liberal arts [21] was included as a personal variable. As the study was conducted at a liberal arts college, this scale was intended to ascertain whether any of the measures of college success included in this study would be affected by how well the student's educational values corresponded with the college's educational mission.

The present study was designed to examine the role of both new and established variables in the Kim et al. [13] model. It was expected that, in addition to the wellestablished academic achievement variables not examined in the present study, both circumstance (ADHD symptoms and parental encouragement of intellectual curiosity) and personal (motives to attend college, study skills, and student appreciation of the liberal arts) variables would be related to success in college as measured by four related but independent factors: grade point average, academic and social adjustment to college, and satisfaction with life. Thus, the present study was designed to replicate and expand Kim et al.'s [13] model.

\section{Method}

2.1. Participants. A total of $45(21 \%)$ males and $171(79 \%)$ females participated. Of these, $158(73 \%)$ were white, 37 (17\%) were African American, 13 (6\%) were Hispanic, 6 (3\%) were Asian American, $1(<1 \%)$ was Native American, and $1(<1 \%)$ declined to answer the question. This distribution generally mirrors the ethnic makeup of the college. Further, 2 (1\%) were freshmen, 32 (15\%) were sophomores, $87(40 \%)$ were juniors, $78(36 \%)$ were seniors, and $17(8 \%)$ were in their fifth year of college or beyond.

A total of $68(31 \%)$ were first-generation college students, $108(50 \%)$ were second-generation, 31 (14\%) were thirdgeneration, and $10(5 \%)$ were fourth-generation college students or beyond. Self-reported grade point averages ranged from 2.0 to $4.0(M=3.22, S D=.53)$.

2.2. Materials and Procedure. Participants were recruited from upper division classes at a northeastern, medium-sized state college with a liberal arts focus. Upper division classes were targeted because upper division students would have had time to adjust to college and to acquire a fairly stable grade point average. Following informed consent, questionnaires were distributed to be returned at the following class session. In addition to demographic information, the surveys contained four measures of college success and five potential predictors of success.

The measures of college success included the following.

2.2.1. Academic and Social Adjustment Subscales of the Student Adaptation to College Questionnaire (SACQ; [6, 7]). The SACQ is a self-report scale that is designed to measure how well a student is adjusting to college, with higher scores on the SACQ indicating higher levels of self-reported adjustment. Several studies have shown the SACQ to have good content and predictive validity [22]. In the present study, internal consistency reliability was good (academic adjustment $\alpha=.84$; social adjustment $\alpha=.81$ ).

2.2.2. Satisfaction with Life Scale [23]. consists of five items scored on a 1 (strongly agree) to 5 (strongly disagree) scale. 
Higher total scores indicate lower levels of current satisfaction with life. In the present study, internal consistency reliability was good $(\alpha=.84)$.

In addition to the above measures, students were asked to report their current grade point average.

Predictors of college success included the following.

2.2.3. Appreciation of the Liberal Arts Scale Revised (ALAS$R$; [21]). This 24-item scale was used to assess students' attitudes toward learning and the degree to which students value the liberal arts. The measure is scored on a 5-point Likert-type scale. The authors report internal consistency of.86. In the present study, internal consistency reliability was $\operatorname{good}(\alpha=.87)$.

2.2.4. College Study Skills Questionnaire [14]. This 11-item scale examines self-reported participation in positive and negative study behaviors. This scale is comprised of questions about habits and skills related to academic achievement (e.g., "I read the textbooks and other assigned readings for my classes"; "I watch TV or listen to music while I study"). Participants used a scale from 1 (Not at all like me) to 4 (Always or very much like me) to rate how closely each item applies to him/her. Six of the items are reversed scored, and a higher overall scale score denotes better study skills. In the present study, internal consistency reliability was acceptable $(\alpha=.74)$.

2.2.5. Conner's Adult ADHD Rating Scale-Short Form (CAARS; [24]). To assess the level of ADHD symptoms, a brief version of the Conner's Adult ADHD Rating Scale (CAARS) was used [24]. The scale was developed to aid in diagnosis of ADHD for individuals ages 18 and above. The brief version consists of 26 items and is comprised of four factors: Inattention/Memory Problems, Hyperactivity/Restlessness, Impulsivity/Emotional Liability, and Problems with Self-Concept. Conners and colleagues [24] reported that observer reports of behavior were moderately to highly correlated with the CAARS-Short Form. The CAARS also includes an ADHD index, designed to identify adults who are likely to be diagnosed with ADHD, as well as an inconsistency index. The present study used the inattention and hyperactivity subscales (Inattention $\alpha=.76$; Hyperactivity $\alpha=.73$ ).

2.2.6. Parental Encouragement of Intellectual Curiosity [20]. This 11-item scale was designed to assess the level of parental encouragement for intellectual curiosity that students received as children. Items included "At least one parent took me to the library" and "At least one parent read to me daily." Items were scored on a 1 (rarely or never) to 4 (very often true) scale in which higher total scores indicated greater encouragement. In the present study, internal consistency reliability was good $(\alpha=.83)$.

2.2.7. Student Motivation for Attending University-Revised [19]. The SMAU-R is comprised of 7 subscales designed to tap different motivations students may have for attending college. These include career/personal (sample item: "To achieve personal success"; 10 items); humanitarian ("To contribute to the welfare of others"; 4 items); default ("There are few other options"; 6 items); expectation ("Parents/family would be very disappointed"; 5 items); prove worth ("To prove to others that I can succeed in college"; 3 items); encouragement ("I was encouraged by a mentor or role model"; 3 items); help family ("It would allow me to help parents/family financially"; 2 items). The authors reported good to strong reliabilities, ranging from .70 (encouragement) to .87 (help family). Items were scored on a 1 (strongly agree) to 5 (strongly disagree) scale. Thus, higher scores indicate lower levels of agreement with each motivation. Subscale composite scores are averages of the items in the factor, to allow comparisons between the subscales. In the present study, internal consistency reliability varied by subscale (career/personal $\alpha=.83$; humanitarian $\alpha=$ .79; prove worth $\alpha=.87$; expectation $\alpha=.76$; encouragement $\alpha=.73$; help family $\alpha=.83$; default $\alpha=.60$ ). Because of the weak reliability of the default subscale, this scale was not included in subsequent analyses.

\section{Results}

3.1. Relations between Collegiate Success Variables. The measures of success in college were related but independent constructs. GPA was significantly correlated only with academic adjustment $(r=.34, P<.001)$. Satisfaction with life was related to academic adjustment $(r=.22, P=.002)$ and social adjustment $(r=.32, P<.001)$. In addition, academic and social adjustment were related to one another $(r=.48$, $P<.001)$.

3.2. Regression Analyses Predicting Success in College. Four regression analyses were completed with the four measures of collegiate success as dependent variables and parental encouragement of intellectual curiosity, inattention, hyperactivity, study skills, and the six motives to attend college as predictors (see Table 1). For three of the regression analyses, collinearity diagnostics indicated no problematic overlap between the variables, with all variance inflation factors (VIFs) well below the accepted threshold of 2.0. For the regression predicting GPA, collinearity diagnostics indicated significant overlap with the humanitarian motives subscale. Consequently, this scale was excluded from the analysis predicting GPA, but was included in the other three regressions.

Only 98 students completed the item asking for GPA. This is likely due to the fact that students had to hand enter this information, rather than filling in a computerscored oval. Among this group, GPA was predicted only by study skills, $R=.43$, Adj. $R^{2}=.09$, and $F(10,88)=$ $2.02, P=.04$. Academic adjustment was predicted by more career-based and encouragement motives to attend college and fewer humanitarian and proving worth motives to attend college, better study skills, and more parental encouragement of intellectual curiosity, $R=.68$, Adj. $R^{2}=.42, F(11,174)=$ 13.27 , and $P<.001$. Social adjustment was predicted by 
TABLE 1: Summary of regression analyses predicting success in college.

\begin{tabular}{|c|c|c|c|c|c|}
\hline Predictor variable & $B$ & SE $B$ & $\beta$ & $t$ & $\alpha$ \\
\hline \multicolumn{6}{|l|}{ GPA } \\
\hline Study skills & .03 & .01 & .38 & 3.12 & .002 \\
\hline Inattention & .02 & .02 & .14 & 1.14 & .26 \\
\hline Hyperactivity & -.03 & .02 & -.17 & -1.60 & .11 \\
\hline ALAS & .01 & .03 & .06 & .48 & .63 \\
\hline Parental encourage. & .01 & .01 & .06 & .61 & .55 \\
\hline Career motives & .08 & .11 & .15 & 1.16 & .25 \\
\hline Prove worth motives & .02 & .05 & .05 & .48 & .63 \\
\hline Expectation motives & .05 & .07 & .08 & .73 & .47 \\
\hline Encouragement motives & .07 & .07 & .13 & 1.10 & .27 \\
\hline Help family motives & .02 & .05 & .04 & .38 & .71 \\
\hline \multicolumn{6}{|l|}{ Academic adjustment } \\
\hline Study skills & .76 & .14 & .38 & 5.36 & $<.001$ \\
\hline Inattention & -.35 & .29 & -.09 & -1.21 & .23 \\
\hline Hyperactivity & -.15 & .24 & -.04 & -.62 & .53 \\
\hline ALAS & 2.17 & 1.50 & .10 & 1.45 & .15 \\
\hline Parental encourage. & .30 & .11 & .16 & 2.67 & .008 \\
\hline Career motives & -5.55 & 1.68 & -.23 & -3.31 & .001 \\
\hline Humanitarian motives & 3.37 & 1.09 & .22 & 3.08 & .002 \\
\hline Prove worth motives & 1.71 & .64 & .17 & 2.67 & .008 \\
\hline Expectation motives & -.00 & .93 & .00 & -.00 & .99 \\
\hline Encouragement motives & -2.14 & .97 & -.16 & -2.22 & .03 \\
\hline Help family motives & -.08 & .66 & -.01 & -.11 & .91 \\
\hline \multicolumn{6}{|l|}{ Social adjustment } \\
\hline Study skills & .22 & .15 & .12 & 1.51 & .13 \\
\hline Inattention & -1.30 & .29 & -.34 & -4.43 & $<.001$ \\
\hline Hyperactivity & .38 & .25 & .10 & 1.49 & .14 \\
\hline ALAS & 3.26 & 1.54 & .16 & 2.11 & .04 \\
\hline Parental encourage. & .21 & .11 & .12 & 1.85 & .07 \\
\hline Career motives & -.85 & 1.68 & -.04 & -.50 & .62 \\
\hline Humanitarian motives & 2.35 & 1.12 & .17 & 2.09 & .04 \\
\hline Prove worth motives & .19 & .67 & .02 & .28 & .78 \\
\hline Expectation motives & -.91 & .96 & -.07 & -.95 & .35 \\
\hline Encouragement motives & -3.63 & .99 & -.28 & -3.66 & $<.001$ \\
\hline Help family motives & -.66 & .68 & -.07 & -.98 & .33 \\
\hline \multicolumn{6}{|l|}{ Satisfaction with life } \\
\hline Study skills & -.04 & .06 & -.06 & -.73 & .46 \\
\hline Inattention & .25 & .12 & .19 & 2.18 & .03 \\
\hline Hyperactivity & .09 & .10 & .07 & .85 & .40 \\
\hline ALAS & .03 & .62 & .00 & .04 & .99 \\
\hline Parental encourage. & -.12 & .05 & -.19 & -2.55 & .01 \\
\hline Career motives & .46 & .69 & .06 & .67 & .51 \\
\hline Humanitarian motives & -.12 & .45 & -.02 & -.28 & .78 \\
\hline Prove worth motives & -.05 & .27 & -.02 & -.19 & .85 \\
\hline Expectation motives & -.39 & .39 & -.08 & -1.00 & .32 \\
\hline Encouragement motives & .56 & .40 & .12 & 1.38 & .17 \\
\hline Help family motives & .13 & .28 & .04 & .48 & .63 \\
\hline
\end{tabular}


fewer symptoms of inattention, greater appreciation of the liberal arts, and more encouragement motives and fewer humanitarian motives to attend college, $R=.58$, Adj. $R^{2}=$ $.30, F(11,176)=8.24, P<.001$. Satisfaction with life was predicted by parental encouragement of intellectual curiosity and fewer symptoms of inattention, $R=.42$, Adj. $R^{2}=.12, F$ $(11,173)=3.36$, and $P<.001$.

\section{Discussion}

The current study was designed to utilize the conceptual framework proposed by Kim et al. [13] to identify predictors of four measures of college success. Three of the five predictors, measures of ADHD symptoms, motives to attend college, and a measure of mastery of study skills, have previously been reported to be predictors of college success. The other two predictors, a measure of parental encouragement for intellectual curiosity and a measure of the correspondence between a student's educational values and the mission of the college they were attending, have not previously been examined as predictors of college success. As expected, student reported GPA was predicted by the measure of their mastery of study skills. Three of the five broad categories of predictors, motives to attend college, better study skills, and more parental encouragement of intellectual curiosity, were linked to academic adjustment. Similarly, social adjustment was also found to be associated with three of the five broad categories of predictors, fewer ADHD symptoms, greater appreciation of the liberal arts, and motives to attend college. The final criterion of college success, Satisfaction with Life, was linked with two of the five broad categories of predictors, parental encouragement of intellectual curiosity, and fewer ADHD symptoms. Thus, all five of the broad predictor categories were associated with at least one of the criterion variables for college success.

In terms of the Kim et al. [13] conceptual framework, one or both of the circumstance variables, which consisted of ADHD symptoms and level of parental encouragement for intellectual curiosity, was linked to three of the four criterion variables, while at least one of the personal variables, which consisted of mastery of study skills, motives to attend college, and the correspondence between student and institutional values, also predicted three of the four criterion variables of student success. As Kim et al. [13] note, finding that personal variables predict measures of college success is encouraging, for these variables are at least potentially amenable to change. And one of these personal variables, appreciation of the liberal arts, has not previously been examined as a predictor of college success.

Despite the intriguing results, there are some limitations to the present study. First, the small sample size and the fact that data were collected at a state college may limit the generalizability of the results. It is possible that students at larger or smaller institutions or private colleges or universities would report a different experience. Further, just under 100 participants reported their grade point averages. There may be something unique about students who choose to report or not to report GPAs, thus limiting confidence in the conclusions. Finally, the parental encouragement of intellectual curiosity and appreciation of the liberal arts measures have not been previously used to examine success in college in the past. Consequently, these results should be considered preliminary and should be replicated in the future.

Future research should examine the importance of a match between student and institutional values in more detail. The current study found that student responses to the Appreciation of the Liberal Arts Scale were associated with increased social adjustment. However, this study was conducted at a liberal arts college. Future research should also examine student responses to this scale at institutions that do not focus on the liberal arts.

In conclusion, the present study replicates previous research in finding that study skills, ADHD symptomatology, and motives to attend college are predictors of various measures of college success. Furthermore, two not previously studied variables, parental encouragement and the correspondence between student and institutional values, were also found to be predictors of measures of college success. These findings thus, extend the number of variables identified as predictors of college success and have implications for college admission decisions as well as for the designing of effective intervention strategies to increase students' college success.

\section{References}

[1] E. E. Emme, "Predicting college success," Journal of Higher Education, vol. 13, pp. 263-267, 1942.

[2] C. Hall, K. Smith, and R. Chia, "Cognitive and personality factors in relation to the timely completion of a degree," College Student Journal, vol. 42, pp. 1087-1098, 2008.

[3] R. Zwick and J. C. Sklar, "Predicting college grades and degree completion using high school grades and SAT scores: the role of student ethnicity and first language," American Educational Research Journal, vol. 42, no. 3, pp. 439-464, 2005.

[4] D. F. McCausland and N. E. Stewart, "Academic aptitude, study skills, and attitudes and college GPA," The Journal of Educational Research, vol. 67, pp. 354-357, 1974.

[5] E. Heiligenstein, G. Guenther, A. Levy, F. Savino, and J. Fulwiler, "Psychological and academic functioning in college students with attention deficit hyperactivity disorder," Journal of American College Health, vol. 47, no. 4, pp. 181-185, 1999.

[6] R. W. Baker and B. Siryk, "Measuring adjustment to college," Journal of Counseling Psychology, vol. 31, no. 2, pp. 179-189, 1984.

[7] R. W. Baker and B. Siryk, Student Adaptation to College Questionnaire (SACQ): Manual, Western Psychological Services, Los Angeles, Calif, USA, 1989.

[8] L. B. Kneipp, B. Cyphers, and K. E. Kelly, "Feeling at peace with college: religiosity, spiritual well-being, and college adjustment," Individual Differences Research, vol. 7, no. 3, pp. 188-196, 2009.

[9] D. C. M. Meehan and C. Negy, "Undergraduate students' adaptation to college: does being married make a difference?" Journal of College Student Development, vol. 44, no. 5, pp. 670690, 2003.

[10] M. Baysden, "International and United States citizen student adaptation to college, opinions about mental illness, and attitudes toward seeking professional counseling help," Dissertation Abstracts International Section A, vol. 64, 2003. 
[11] A. Borrello, "Subjective well-being and academic success among college students," Dissertation Abstracts International, vol. 66, 2005.

[12] J. W. Lounsbury, L. A. Fisher, J. J. Levy, and D. P. Welsh, "An investigation of character strengths in relation to the academic success of college students," Individual Differences Research, vol. 7, no. 1, pp. 52-69, 2009.

[13] E. Kim, F. B. Newton, R. G. Downey, and S. L. Benton, "Personal factors impacting college student success. Constructing College Learning Effectiveness Inventory (CLEI)," College Student Journal, vol. 44, no. 1, pp. 112-125, 2010.

[14] K. Norwalk, J. M. Norvilitis, and M. G. MacLean, "ADHD symptomatology and its relationship to factors associated with college adjustment," Journal of Attention Disorders, vol. 13, no. 3, pp. 251-258, 2009.

[15] J. M. Norvilitis, L. Sun, and J. Zhang, "ADHD symptomatology and adjustment to college in China and the United States," Journal of Learning Disabilities, vol. 43, no. 1, pp. 86-94, 2010.

[16] S. B. Robbins, K. Lauver, H. Le, D. Davis, R. Langley, and A. Carlstrom, "Do psychosocial and study skill factors predict college outcomes? A meta-analysis," Psychological Bulletin, vol. 130, no. 2, pp. 261-288, 2004.

[17] F. Schab, "Reasons for attending college as reported by female students in a southern university," Florida Journal of Educational Research, vol. 16, pp. 55-58, 1974.

[18] J. Whitehead, "Motives for higher education: a study of intrinsic and extrinsic motivation in relation to academic attainment," Cambridge Journal of Education, vol. 14, no. 2, pp. 26-34, 1984.

[19] J. S. Phinney, J. Dennis, and S. Osorio, "Reasons to attend college among ethnically diverse college students," Cultural Diversity and Ethnic Minority Psychology, vol. 12, no. 2, pp. 347-366, 2006.

[20] J. M. Norvilitis, H. M. Reid, S. Ling, and S. Chen, "Motivation to attend college: A comparison of American and Chinese students, and the effects of ADHD symptomatology and personality upon their motivation," Journal of the First Year Experience and Students in Transition. In press.

[21] H. M. Reid, K. O'Quin, and B. Kline, "Development of a revised appreciation of the liberal arts scale," in Proceedings of the Eastern Psychological Association Convention, New York, NY, USA, 2010.

[22] J. E. Asher, Review of the Student Adaptation to College Questionnaire, vol. 11, Mental Measurements Yearbook, 2004.

[23] E. Diener, R. A. Emmons, R. J. Larsen, and S. Griffin, "The satisfaction with life scale," Journal of Personality Assessment, vol. 49, no. 1, pp. 71-75, 1985.

[24] C. K. Conners, D. Erhardt, J. N. Epstein, J. D. A. Parker, G. Sitarenios, and E. Sparrow, "Self-ratings of ADHD symptoms in adults-I: factor structure and normative data," Journal of Attention Disorders, vol. 3, no. 3, pp. 141-151, 1999. 


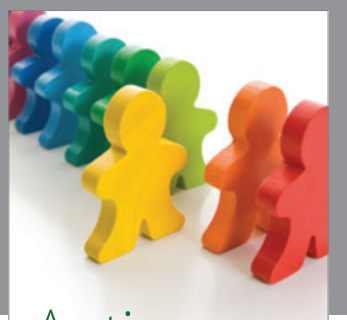

Autism

Research and Treatment
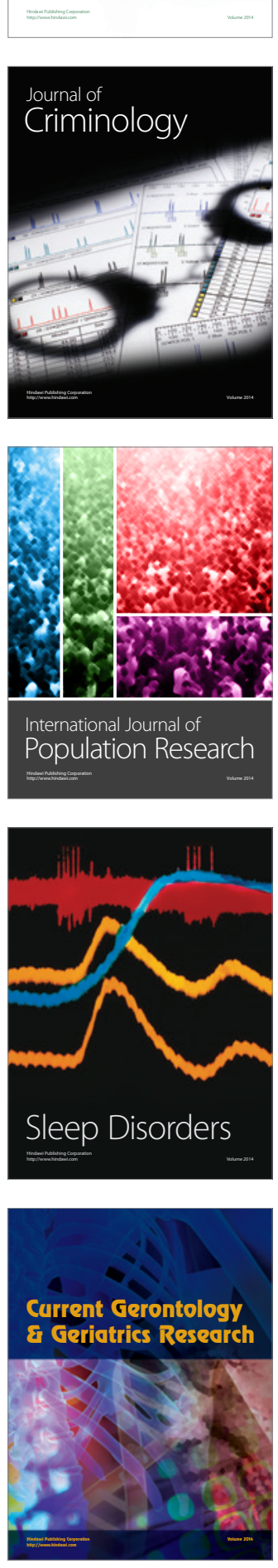
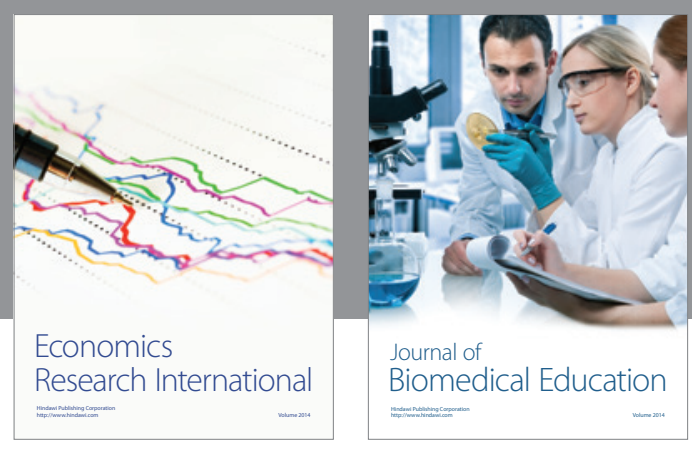

Journal of

Biomedical Education

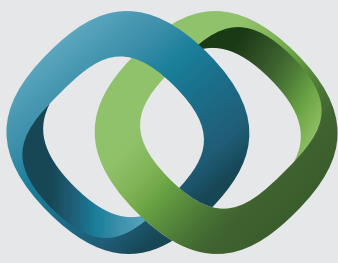

\section{Hindawi}

Submit your manuscripts at

http://www.hindawi.com
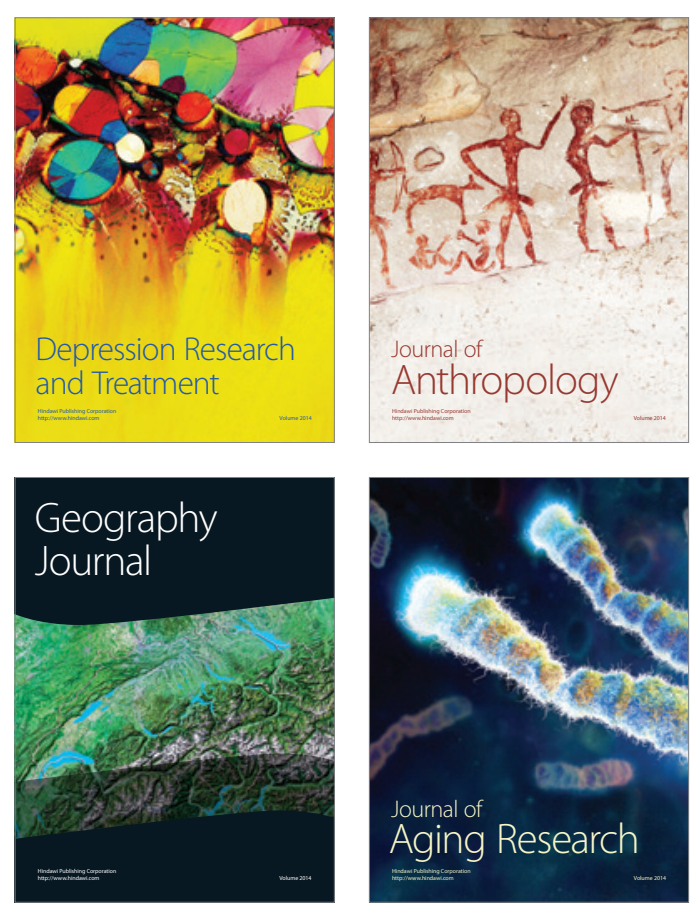

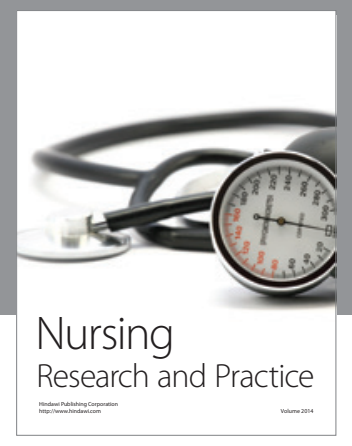

Nursing

Research and Practice

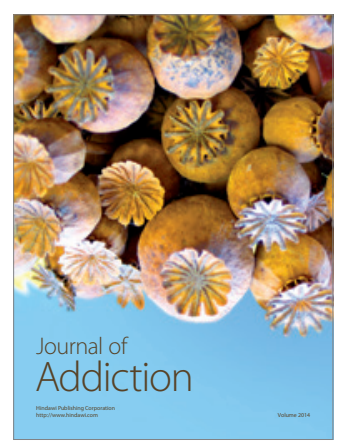

Child Development

Research

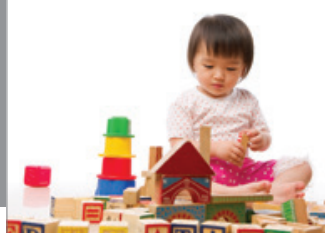

迥
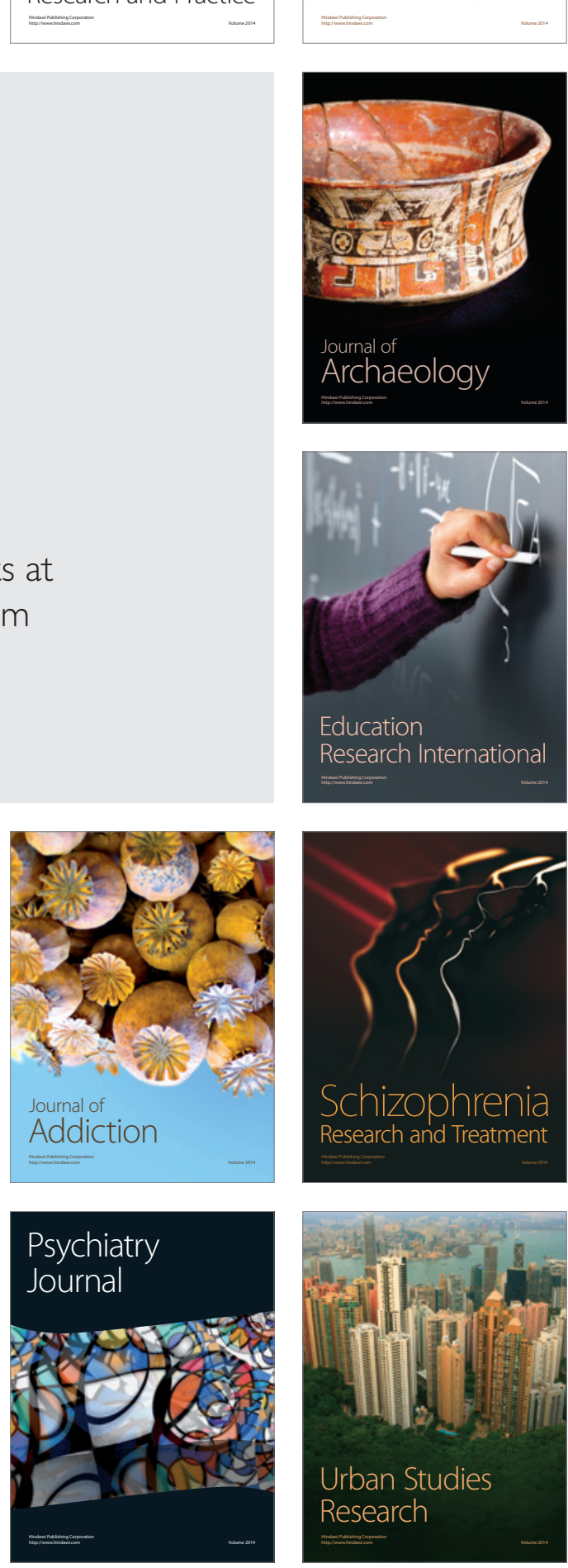